\title{
ARTICLE
}

\section{Absorbent property of fullerene for cesium isotope separation investigated using X-ray photoelectron spectroscopy}

\author{
Tetsuhiro Sekiguchi $^{\mathrm{a}^{*}}$, Keiichi Yokoyama ${ }^{\mathrm{a}}$, Yuki Uozumi ${ }^{\mathrm{b}, \mathrm{c}}$, Masahiro Yano ${ }^{\mathrm{c}}$, \\ Hidehito Asaoka ${ }^{c}$, Shinichi Suzuki ${ }^{\mathrm{a}}$ and Tsuyoshi Yaita ${ }^{\mathrm{a}}$
}

\begin{abstract}
a Japan Atomic Energy Agency, Materials Science Research Center, 2-4 Shirakata, Tokai-mura, Naka-gun, Ibaraki, 319-1195, Japan; ${ }^{b}$ Hitachi Power Solutions, Saiwai-cho, Hitachi, Ibaraki, 317-0073, Japan; ' Japan Atomic Energy Agency, Advanced Science Research Center, 2-4 Shirakata, Tokai-mura, Naka-gun, Ibaraki, 319-1195, Japan
\end{abstract}

For isotope separation of cesium (Cs)-135, the amount of Cs atom or cesium iodide (CsI) that was selectively absorbed into Buckminster-Fullerene $\left(\mathrm{C}_{60}\right)$ was evaluated. For $\mathrm{C}_{60}$ solid surface exposed to $\mathrm{Cs}$ atom or $\mathrm{CsI}$ molecule, depth concentration profiles were investigated using angle-resolved X-ray photoelectron spectroscopy. $\mathrm{Cs}$ atom was found to penetrate toward $\mathrm{C}_{60}$ bulk. In contrast, $\mathrm{C}_{60}$ did not absorb CsI molecule into deep.

Keywords: Cesium-135; isotope separation; Buckminster-Fullerene $C_{60} ; X$-ray photoelectron spectroscopy (XPS)

\section{Introduction}

Among long lived fission products, cesium-135 $\left({ }^{135} \mathrm{Cs}\right)$ with a half-life of 2.3 million years is an important target for nuclear transmutation next to iodine-129 and technetium-99. It has been pointed out that existence of stable isotope ${ }^{133} \mathrm{Cs}$ greatly deteriorates a net reduction of ${ }^{135} \mathrm{Cs}$ owing to the creation of ${ }^{135} \mathrm{Cs}$ by double neutron capture [1]. Thus, technological development on isotopic separation of ${ }^{135} \mathrm{Cs}$ from ${ }^{133} \mathrm{Cs}$ in prior to transmutation is important.

Recently, a concept of new laser isotope-selective dissociation scheme by frequency comb technique using a terahertz-wave field is proposed for diatomic molecules like cesium iodide molecule $\left({ }^{133} \mathrm{CsI} /{ }^{135} \mathrm{CsI}\right)$ in the gas-phase [2]. Thus, only ${ }^{135} \mathrm{CsI}$ isotope selectively dissociates to ${ }^{135} \mathrm{Cs}$ atom, leaving intact ${ }^{133} \mathrm{CsI}$ molecule.

However, one important requirement that still exists is the preferential recovery reaction of ${ }^{135} \mathrm{Cs}$ atom to ${ }^{133} \mathrm{CsI}$, because the collision between ${ }^{135} \mathrm{Cs}$ atom and ${ }^{133} \mathrm{CsI}$ molecule causes isotope-exchange to form ${ }^{135} \mathrm{CsI}$ and ${ }^{133} \mathrm{Cs}$ [3]. Therefore, we need to develop a selective absorbent which takes only Cs atom into deep rather than CsI.

In this study, we chose Buckminster fullerene $\left(\mathrm{C}_{60}\right)$ as an absorbent. We investigated how $\mathrm{Cs}$ atom or CsI molecule was absorbed into $\mathrm{C}_{60}$ using angle-resolved $\mathrm{X}$-ray photoelectron spectroscopy (AR-XPS). AR-XPS is non-destructive and known to analyze depth concentration distribution at nanometer scale

*Corresponding author. Email: sekiguchi.tetsuhiro@jaea.go.jp corresponding to several $\mathrm{C}_{60}$ molecules. We compared the absorbing property and evaluated absorbent selectivity.

\section{Experiments}

Experiments were performed using beamline-27A in Photon Factory of High Energy Acceleration Research Organization. Photoelectron was excited by X-rays from double-crystal monochromator with InSb(111). A detailed description of the apparatus is reported elsewhere [4]. Briefly, an analyzing chamber (base pressure $1 \times 10^{-7} \mathrm{~Pa}$ ) was equipped with XPS system with a spherical electron energy analyzer (VSW Co., CLASS100) and a sputter ion-gun. The preparation chamber was equipped with K-cells (AVC Co.) for $\mathrm{C}_{60}$ (Aldrich Co., 99\%) and CsI (Kanto Chem. Co., 99.99\%), and $\mathrm{Cs}$ alkali metal dispenser (SAES Co., CS/NF/3.9/12FT10), a thickness monitor (INFICON Co., $\mathrm{STM} / 2$ ), and a quadrupole mass spectrometer (SRS Co., RGA200) for monitoring relative flux of Cs or CsI species during deposition. Sample films were prepared in the vacuum chamber, and transferred to the analyzing chamber that was connected to synchrotron beam-line.

Si(111) substrates were cleaned by repeated $\mathrm{Ar}^{+}$-sputtering. Through the $\mathrm{K}$-cell heated at $750 \mathrm{~K}, \mathrm{C}_{60}$ was grown on the $\mathrm{Si}$ substrates. On $\mathrm{C}_{60}$ films, Cs atom or CsI was dosed from the SAES getter source $\left(\mathrm{Cs}_{2} \mathrm{CrO}_{4}\right)$ or CsI powder, respectively. Typical deposition rates were ca. $0.02 \AA / \sec \left(\mathrm{C}_{60}\right), 0.03 \AA / \mathrm{sec}$ (Cs), and 0.005 $\AA / \mathrm{sec}$ (CsI), which were recorded by the thickness monitor. 


\section{Results and discussion}

Figures 1a and 1b show X-ray photoelectron spectra for a Cs dosed $\mathrm{C}_{60}$ (hereafter, we abbreviate it as $\mathrm{Cs} / \mathrm{C}_{60}$ ) film and for CsI deposited on $\mathrm{C}_{60}\left(\mathrm{CsI} / \mathrm{C}_{60}\right)$, respectively, which covered $\mathrm{Cs} 3 d_{5 / 2}, 3 / 2$, I $3 d_{5 / 2}, 3 / 2$, and $\mathrm{C} 1 s$ regions. To obtain depth concentration profiles of $\mathrm{Cs}$ atom, photoelectron spectra were measured at various electron emission angles $(\theta)$ defined as between the electron energy analyzer direction and the surface normal $(\theta=$ $\left.0^{\circ}\right)$. It was found that the angular dependence of intensity of $\mathrm{C} 1 s$ relative to $\mathrm{Cs} 3 d$ differed between $\mathrm{Cs} / \mathrm{C}_{60}$ and $\mathrm{CsI} / \mathrm{C}_{60}$. In Figure $1 \mathrm{~b}$, we can see that relative $\mathrm{C}-1 s$ intensity decreased at $\theta=68^{\circ}$ compared with that at $\theta=7^{\circ}$

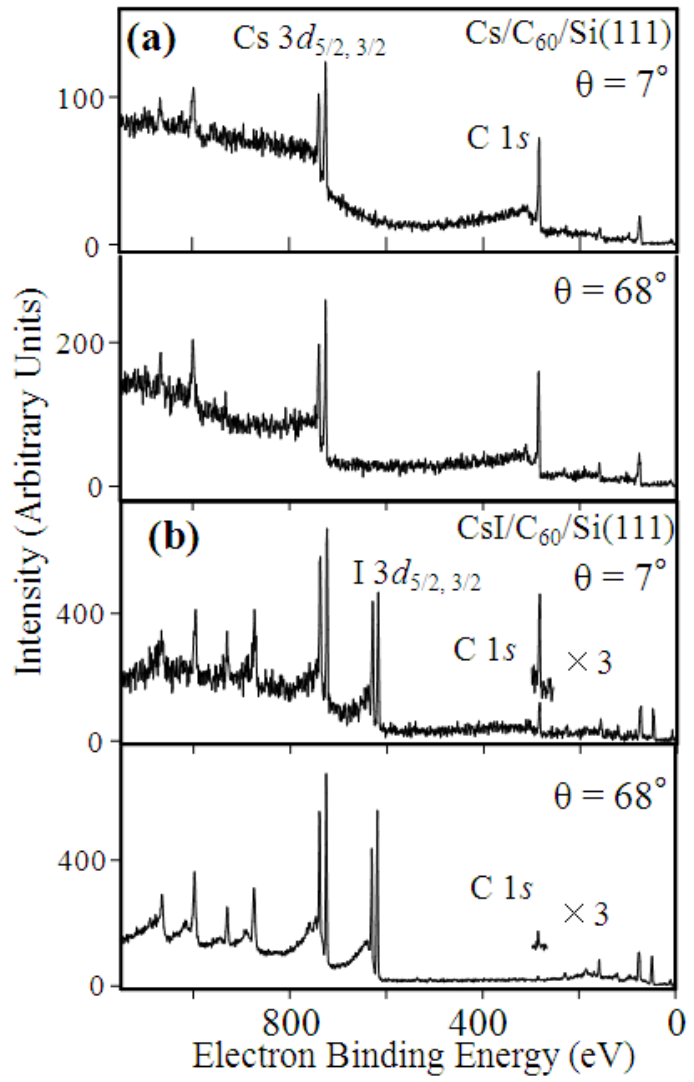

Figure 1. X-ray photoelectron spectra measured with photon energy of $2200 \mathrm{eV}$ for (a) Cs-dosed on $\mathrm{C}_{60}$ film and for (b) CsI-deposited on $\mathrm{C}_{60}$ film. Electron emission angles $(\theta)$ are indicated on the right top.

This difference was further evidenced in Figure 2 that shows integrated intensities of $\mathrm{Cs} 3 d_{5 / 2,3 / 2}$ (or I $3 d_{5 / 2,3 / 2}$ ) and $\mathrm{C} 1 s$ (labeled $\times$ ) plotted as a function of $\theta$, although there was a trend that detection efficiencies decreased with increasing $\theta$. Photoelectron intensities in Figure 2 were corrected by electron kinetic energy dependencies of analyzer transmission functions $(F)$ for the equipment used and by partial photoionization cross sections $(\sigma)$. The $F$ values were determined by separately measuring standard materials. Theoretical $\sigma\left(\operatorname{Cs~} 3 d_{5 / 2}\right)=116000, \sigma\left(\operatorname{Cs} 3 d_{3 / 2}\right)=81400, \sigma\left(\mathrm{I} 3 d_{5 / 2}\right)=$ $95900, \sigma\left(\mathrm{I} 3 d_{3 / 2}\right)=53500$, and $\sigma(\mathrm{C} 1 s)=4800$ barns for $\mathrm{h} v=2200 \mathrm{eV}$ photon were used [5].

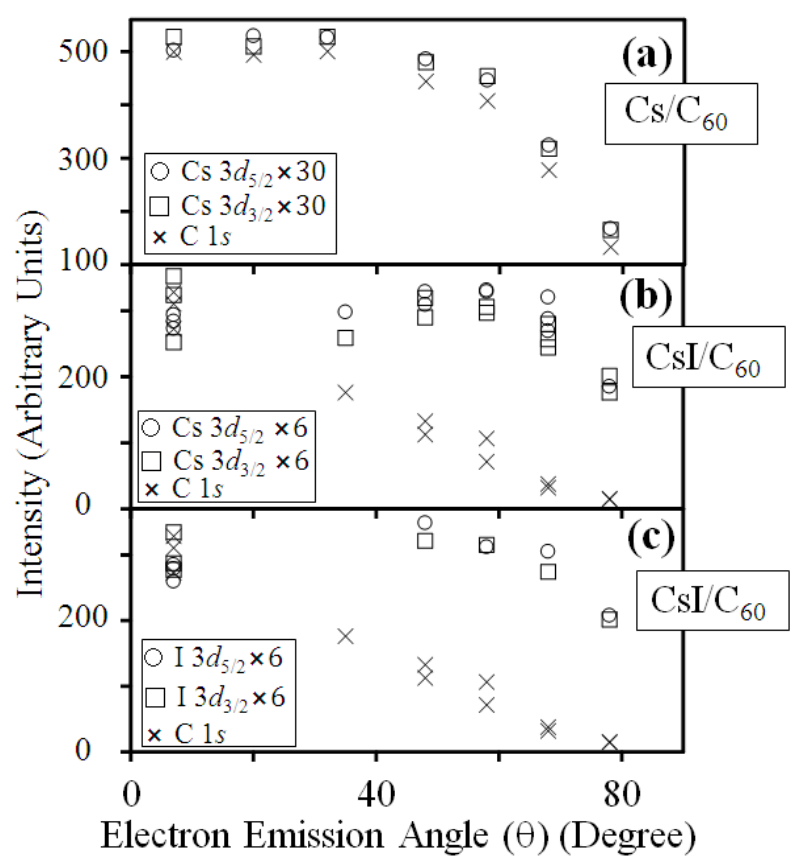

Figure 2 (a) Intensities of $\mathrm{Cs} 3 d_{5 / 2}, 3 / 2$ and $\mathrm{C} 1 s$ peaks as a function of electron emission angles $\theta$, which were measured for Cs-dosed $\mathrm{C}_{60}$ film. Intensities of (b) Cs $3 d_{5 / 2}, 3 / 2$ and $\mathrm{C} 1 s$ and (c) I $3 d_{5 / 2}, 3 / 2$ and $\mathrm{C} 1 \mathrm{~s}$ peaks measured for CsI- deposited $\mathrm{C}_{60}$ film.

A key finding is the fact in $\mathrm{Cs} / \mathrm{C}_{60}$ (Figure $2 \mathrm{a}$ ) that the angular dependence of relative $\mathrm{C} 1 s$ intensities (labeled $\mathbf{x}$ ) was not prominent and also similar to that of $\mathrm{Cs}$ $3 d_{5 / 2,3 / 2}$ intensities, suggesting that $\mathrm{Cs}$ and carbon concentration did not apparently change between shallow and deep regions for $\mathrm{Cs} / \mathrm{C}_{60}$. In contrast, as for $\mathrm{CsI} / \mathrm{C}_{60}$ (Figures $2 \mathrm{~b}$ and $2 \mathrm{c}$ ), the relative $\mathrm{C} 1 s$ intensities (labeled $\times$ ) gradually decreased by increasing $\theta$ angles. This observation can be qualitatively explained by considering that detection depths became shallow at large $\theta$ angles. Detection depth was estimated to be roughly three times of inelastic mean free path (IMFP or $\lambda)$ times $\cos (\theta)$. In fact, the detection depths were calculated to be $171 \AA$ at near the right-angle detection $\left(\theta=7^{\circ}\right)$ and $33 \AA$ at the grazing detection $\left(\theta=78^{\circ}\right)$, on the basis of $\lambda_{\text {CsI }}$ (here, $\lambda_{\text {CsI }}$ denotes IMFP in which photo-electrons pass through CsI medium) of C $1 s$ for $\mathrm{h} v=2200 \mathrm{eV}$ photon. So, we assume that the decrease in the $\mathrm{C} 1 s$ intensity for $\mathrm{CsI} / \mathrm{C}_{60}$ suggests low carbon concentration at shallow surface compared with deep.

The measured integrated intensity $\mathrm{I}(\theta)$ at various angles $\theta$ can be expressed in the following equation [6]:

$$
\mathrm{I}(\theta)=\frac{\mathrm{F} \cdot \mathrm{D} \cdot \mathrm{K}}{\cos \theta} \sigma \int_{0}^{\infty} \mathrm{dzf}(\mathrm{z}) \exp \left(\frac{-\mathrm{z}}{\lambda \cos \theta}\right)
$$

where $\mathrm{f}(\mathrm{z})$ is the atomic density at depth $\mathrm{z}, \mathrm{D}$ is the detection efficiency, $\mathrm{K}$ includes $\mathrm{X}$-ray flux and other 
dependencies related with the instrument. As seen in Figure 2, photoelectron intensities were strongly influenced by angular dependencies of F, D, K, and $1 / \cos (\theta)$ in Eq. (1). However, such angular dependencies may be eliminated by calculating fractional intensities, e.g. $\mathrm{I}_{\mathrm{Cs} 3 d} /\left(\mathrm{I}_{\mathrm{Cs} 3 d}+\mathrm{I}_{\mathrm{C} 1 \mathrm{~s}}\right)$, as a function of angles $\theta$.

Figure 3 shows fractional intensities of $\mathrm{Cs} 3 d_{5 / 2,3 / 2}$, $\mathrm{I}-3 d_{5 / 2,3 / 2}$, and $\mathrm{C} 1 s$ for $\mathrm{Cs} / \mathrm{C}_{60}$ (Figure $3 \mathrm{a}$ ) and $\mathrm{CsI} / \mathrm{C}_{60}$ (Figures $3 \mathrm{~b}, 3 \mathrm{c}$ ). Again, gradual dependence in $\mathrm{Cs} 3 d_{5 / 2}$, $3 / 2$ and $\mathrm{C} 1 s$ was observed for $\mathrm{Cs} / \mathrm{C}_{60}$, while marked angular dependence was shown in Cs $3 d_{5 / 2,3 / 2}$ (or I $3 d_{5 / 2 \text {, }}$ $3 / 2$ ) and $\mathrm{C} 1 s$ for $\mathrm{Cs} / \mathrm{C}_{60}$. Moreover, the results confirm that relative $\mathrm{C} 1 s$ intensity decreased by increasing angles $\theta$. These observations consistently support the above-mentioned view that $\mathrm{Cs}$ was mixed into $\mathrm{C}_{60}$ bulk, whilst CsI was deposited on $\mathrm{C}_{60}$ surface forming over-layer.

To understand quantitatively, we postulated an over-layer model in which a uniform film was formed on the $\mathrm{C}_{60}$ surface. Considering CsI thin film on $\mathrm{C}_{60}$, the intensity of $\mathrm{Cs} 3 d$ or $\mathrm{C} 1 s$ is expressed as,

$$
\begin{aligned}
& \mathrm{I}(\mathrm{Cs} 3 d)=\mathrm{K}(\theta) \sigma(\mathrm{Cs} 3 d) \lambda_{\mathrm{Csl}}(\mathrm{Cs} 3 d) \mathrm{n}(\mathrm{Cs})\left[1-\exp \left(\frac{-d}{\lambda_{\mathrm{CsI}}(\mathrm{Cs} 3 d) \cos \theta}\right)\right] \\
& \mathrm{I}(\mathrm{C} 1 s)=\mathrm{K}(\theta) \sigma(\mathrm{C} 1 s) \lambda_{\mathrm{C} 60}(\mathrm{C} 1 s) \mathrm{n}(\mathrm{C}) \exp \left(\frac{-d}{\lambda_{\mathrm{Csl}}(\mathrm{C} 1 s) \cos \theta}\right)
\end{aligned}
$$

where $d$ is thickness of postulated CsI over-layer, $\mathrm{K}(\theta)$ includes angular dependencies related with the instrument. Equations 2 and 3 are special cases of Eq. (1). IMFPs were calculated to be $\lambda_{\text {CsI }}\left(\operatorname{Cs} 3 d_{5 / 2,3 / 2}\right)=46.4 \AA$,

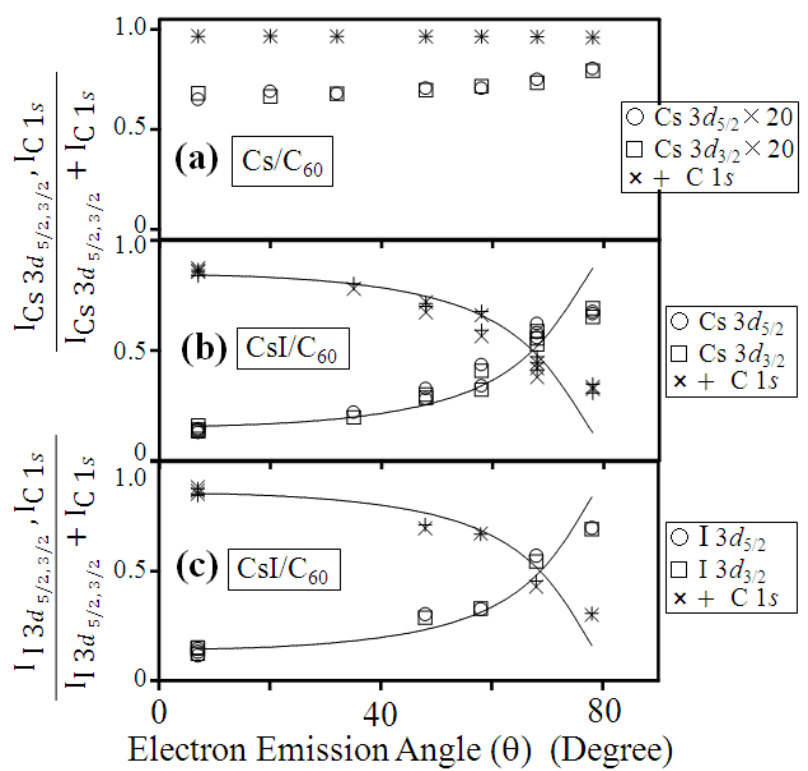

Figure 3. Fractional intensities, e.g. $\mathrm{I}_{\mathrm{Cs} 3 d} /\left(\mathrm{I}_{\mathrm{Cs} 3 d}+\mathrm{I}_{\mathrm{C} 1 \mathrm{~s}}\right)$, of (a) Cs $3 d_{5 / 2,3 / 2}$ peaks as a function of electron emission angles $(\theta)$, which were measured for Cs- dosed $\mathrm{C}_{60}$ film. Those of (b) Cs $3 d_{5 / 2,3 / 2}$ and (c) I $3 d_{5 / 2,3 / 2}$ peaks measured for CsI- deposited $\mathrm{C}_{60}$ film. Full lines show the best fitted curves calculated by assuming a uniform CsI-over-layered model.
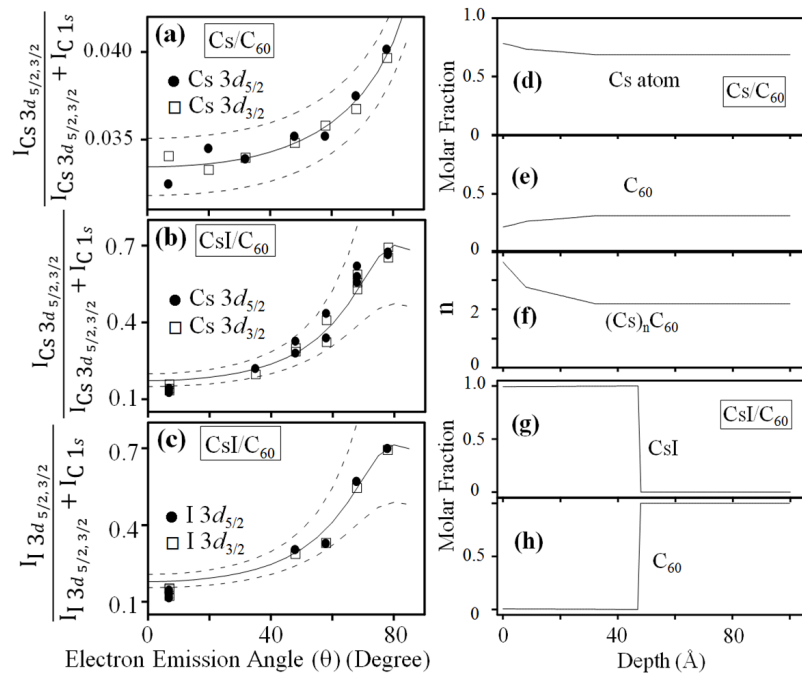

Figure 4. On the left, enlarged fractional intensity plots of (a) Cs $3 d$ 5/2,3/2 peaks for Cs-dosed $\mathrm{C}_{60}$ film, along with the best fit curves. Those of (b) Cs $3 d_{5 / 2}, 3 / 2$ and (c) I $3 d_{5 / 2}, 3 / 2$ for CsI-deposited $\mathrm{C}_{60}$ film. On the right, the most probable depth molar-fractional profiles (d), (e), and ratio $\mathrm{n}(\mathrm{f})$ for Cs-dosed $\mathrm{C}_{60}$ film and those $(\mathrm{g})$ and $(\mathrm{h})$ for CsI-deposited $\mathrm{C}_{60}$ film. Broken lines show curves assuming $\pm 6 \%$ deviations from the best Cs molar fractions.

$\lambda_{\mathrm{CsI}}\left(\mathrm{I} 3 d_{5 / 2,3 / 2}\right)=49.1 \AA, \lambda_{\mathrm{CsI}}(\mathrm{C} 1 s)=57.2 \AA, \lambda \mathrm{C}_{60}(\mathrm{C} 1 s)$ $=45.2 \AA$ for $\mathrm{h} v=2200 \mathrm{eV}$ based on TPP2M method [7]. Atomic densities are $\mathrm{n}(\mathrm{Cs})=1.73 \times 10^{-2}$ and $\mathrm{n}(\mathrm{C})=0.143$ $\left[\mathrm{mol} \mathrm{cm}{ }^{-3}\right]$ for crystalline $\mathrm{CsI}$ and $\mathrm{C}_{60}$, respectively. Figures $3 b$ and $3 c$ depict the best-fit curves which give the thickness (d) of CsI over-layer being $48 \AA$ (Cs $\left.3 d_{5 / 2}\right)$, $46 \AA$ (Cs $\left.3 d_{3 / 2}\right), 44 \AA$ (I $3 d_{5 / 2}$ ), and $43 \AA$ (I $3 d_{3 / 2}$ ) for $\mathrm{CsI} / \mathrm{C}_{60}$. It is noteworthy that $\mathrm{Cs} 3 d_{5 / 2,3 / 2}$ and I $3 d_{5 / 2,3 / 2}$ data gave consistent thickness. As for $\mathrm{Cs} / \mathrm{C}_{60}$ (Figure 3a), on the other hand, the fitting routine could not find any suitable solutions and ended in failed error because C $1 s$ intensity did not decrease by increasing angles $\theta$. Considering the nature that $\mathrm{Cs}$ atoms were mixed in $\mathrm{C}_{60}$ solid, it is consistent that over-layer hypothesis is not valid for $\mathrm{Cs} / \mathrm{C}_{60}$.

To understand how $\mathrm{Cs}$ atom penetrated into $\mathrm{C}_{60}$, we tried to convert the angle-dependent photoemission intensities to molar compositions as a function of depth. We postulated a model depth profile containing concentration gradients constructed from three linear segments, which has been modeled by Paynter [6]. This model contains the quantities of concentrations $c_{i}$ at the depth $z_{i}, i=1,2$, or 3 . The intensity calculation takes the sum over each linear segment; that is,

$\mathrm{I}=\mathrm{I}_{1}\left(\mathrm{c}_{1}, \mathrm{z}_{1}(=0) \rightarrow \mathrm{c}_{2}, \mathrm{z}_{2}\right)+\mathrm{I}_{2}\left(\mathrm{c}_{2}, \mathrm{z}_{2} \rightarrow \mathrm{c}_{3}, \mathrm{z}_{3}\right)+\mathrm{I}_{3}\left(\mathrm{c}_{3}, \mathrm{z}_{3} \rightarrow \mathrm{c}_{3}, \infty\right)$

We profiled cesium distributions by the procedure described below. First, Eq. (1) was numerically integrated assuming independent variables. Next, angular profiles of fractional intensities, e.g. $\mathrm{I}_{\mathrm{Cs} 3 d} /\left(\mathrm{I}_{\mathrm{Cs} 3 d}\right.$ $+\mathrm{I}_{\mathrm{Cls}}$ ), were calculated. Finally, the sums of weighted squares error (chi squares) were calculated, 


$$
\chi^{2}=\sum_{\mathrm{k}} \frac{\left(\mathrm{Fr}_{\mathrm{k}}^{\mathrm{calc}}-\mathrm{Fr}_{\mathrm{k}}^{\mathrm{obs}}\right)^{2}}{\sigma_{\mathrm{k}}^{2}}
$$

where $\sigma_{\mathrm{k}}$ represents the standard deviation in the k-th measurement at an angle $\theta_{\mathrm{k}}$; and $\mathrm{F}_{\mathrm{r}_{k}}^{\text {calc }}$ and $\mathrm{F}_{\mathrm{r}_{k}}^{\text {obs }}$ show calculated and experimental fractional intensities, respectively. The aforementioned calculations were repeated until the chi squares were minimized using a generalized-reduced-gradient fitting routine. In calculating Eq. (1), treating $\lambda$ as constant gave qualitatively the same result. But, for accurate calculation we used the following formula in integration in the case of $\mathrm{CsI} / \mathrm{C}_{60}$,

$$
\lambda_{\text {mixture }}(\mathrm{Cs} 3 d)=\frac{1}{\frac{\mathrm{m}(\mathrm{CsI})}{\lambda_{\mathrm{CsI}}(\mathrm{Cs} 3 d)}+\frac{\mathrm{m}\left(\mathrm{C}_{60}\right)}{\lambda_{\mathrm{C}_{60}}(\mathrm{Cs} 3 d)}}
$$

$$
\lambda_{\text {mixture }}(\mathrm{C} 1 s)=\frac{1}{\frac{\mathrm{m}(\mathrm{CsI})}{\lambda_{\mathrm{CsI}}(C 1 s)}+\frac{\mathrm{m}\left(\mathrm{C}_{60}\right)}{\lambda_{\mathrm{C}_{60}}(C 1 s)}}
$$

where $\mathrm{m}(\mathrm{CsI})$ and $\mathrm{m}\left(\mathrm{C}_{60}\right)$ are molar fractions. In the case of $\mathrm{Cs} / \mathrm{C}_{60}, \lambda_{\text {mixture }}(\mathrm{Cs} 3 d)$ and $\lambda_{\text {mixture }}(\mathrm{C} 1 s)$ in integration of Eq. (1) were taken as a function of depth $\mathrm{z}$ and calculated based on TPP2M formulae with densities that were corrected considering an approximate linear relation between molecular weight of $\mathrm{Cs}_{\mathrm{n}} \mathrm{C}_{60}$ and its density under $\mathrm{n}<8[8]$.

Figures 4 a-c show the best fitted fractional intensity curves. Figures 4 d-h show the obtained depth profiles of molar fractions for $\mathrm{Cs}$ or $\mathrm{CsI}$ versus $\mathrm{C}_{60}$, e.g. $[\mathrm{Cs}] /\left([\mathrm{Cs}]+\left[\mathrm{C}_{60}\right]\right)$. It is well- known that depth profile is not uniquely determined from a set of experimental data [6]. Even so, different characteristics were clearly obtained between $\mathrm{Cs} / \mathrm{C}_{60}$ and $\mathrm{CsI} / \mathrm{C}_{60}$. As for $\mathrm{Cs} / \mathrm{C}_{60}$, concentration $c_{3}(\mathrm{Cs}) \quad(=0.68$, molar fraction, i.e., $[\mathrm{Cs}] /\left([\mathrm{Cs}]+\left[\mathrm{C}_{60}\right]\right)$ at $\mathrm{z}_{3}(=32 \AA) \rightarrow \infty$ tended to be close to $\mathrm{c}_{2}(\mathrm{Cs})(=0.73)$ at $\mathrm{z}_{2}(=8 \AA)$, indicating that the Cs concentration was maintained into deep bulk as shown in Figure 4d. We found in Figure $4 \mathrm{f}$ that as typical ratio $\mathrm{Cs}_{3.6} \mathrm{C}_{60}$ at surface and $\mathrm{Cs}_{2.2} \mathrm{C}_{60}$ at bulk were estimated for $\mathrm{Cs} / \mathrm{C}_{60}$. In contrast, as for $\mathrm{CsI} / \mathrm{C}_{60}$ the concentration $\mathrm{c}_{3}(\mathrm{CsI})\left(=0.0\right.$, i.e., $[\mathrm{CsI}] /\left([\mathrm{CsI}]+\left[\mathrm{C}_{60}\right]\right)$ at $\mathrm{z}_{3}(=47 \AA)$ tended to be nearly zero, as shown in Figure $4 \mathrm{~g}$. Although a certain amount of CsI was deposited on the $\mathrm{C}_{60}$ surface, we consider that CsI molecule did not penetrate into bulk but stopped at a barrier interface between $\mathrm{CsI}$ and $\mathrm{C}_{60}$ phases.

\section{Conclusion}

We investigated the property of $\mathrm{C}_{60}$ solid as an absorbent for Cs atom or CsI molecule using the angle-resolved XPS technique. Unusual angular independencies were observed for Cs-dosed $\mathrm{C}_{60}$, while over-layer-like ordinary angular dependencies were recorded for CsI-deposited $\mathrm{C}_{60}$. This observed difference was interpreted as the different penetrating abilities between $\mathrm{Cs}$ and $\mathrm{CsI}$ into the $\mathrm{C}_{60}$ solid. Thus, the present results show that $\mathrm{C}_{60}$ may become a candidate for Cs-selective absorbent material that prevents ${ }^{135} \mathrm{Cs}$ and ${ }^{133} \mathrm{CsI}$ from collision. For realizing the ideal situation that CsI does not stick on the $\mathrm{C}_{60}$ surface, experiments with heating substrates are in progress.

\section{Acknowledgements}

The authors wish to thank Drs. Y. Okamoto and I. Shimoyama of JAEA, Prof. N. Usami and the staff of Photon Factory KEK for the helpful support during synchrotron experiments performed under PF-PAC (No. 2016G-188). This work was supported by JSPS KAKENHI [grant number 15H02345].

\section{References}

[1] S. Ohki and N. Takaki, Transmutation of cesium-135 with fast reactors, 7-th Information Exchange Meeting on Actinide and Fission Product Partitioning and Transmutation, OECD/NEA No. 5990, Oct. 2002, Jeju, Repub. Korea, (2002), pp.14-16.

[2] A. Ichihara, L. Matsuoka, Y. Kurosaki and K. Yokoyama, Theoretical study on isotope-selective dissociation of the lithium chloride molecule using a designed terahertz-wave field, Proc.12th-Asia Pacific Phys. Conf. (APPC12), JPS Conf. Proc. 1 (2014) pp. 013093-1, 013093-4.

[3] T. Kobayashi, M. Hashimoto and K. Yokoyama, Theoretical Study of the Cs Isotope Exchange Reaction of CsI + Cs' $\rightarrow$ Cs + ICs', JAEA-Research, 2015-014, (2015), pp. 1-7 (in Japanese).

[4] H. Konishi, A. Yokoya, H. Shiwaku, H. Motohashi, T. Makita, Y. Kashiwara, S. Hashimoto, T. Harami, T.A. Sasaki, H. Maeta, H. Ohno, H. Maezawa, S. Asaoka, N. Kanaya, K. Ito, N. Usami and K. Kobayashi, Synchrotron radiation beamline to study radioactive materials at the Photon Factory, Nucl. Inst. Meth. Phys. Res. Sec.-A 372 (1996), pp. 322-332.

[5] J.H. Scofield, Theoretical photoionization cross sections from 1 to $1500 \mathrm{keV}$; Lowrence Livermore Laboratory Report, TID-4500, UC-34 Physics, UCRL-51326 (1973), pp. 144-147.

[6] R.W. Paynter, Modification of the Beer-Lambert equation for application to concentration gradients, Surf. Interf. Anal. 3 (1981), pp. 186-187.

[7] S. Tanuma, C.J. Powell and D.R. Penn, Calculations of electron inelastic mean free paths. V. Data for 14 organic compounds over the 50-2000 eV range, Surf. Interf. Anal. 21 (1994), pp.165-176.

[8] H-N. Li, X-X. Wang and W-F. Ding, Electron attenuation lengths in fullerene and fullerides, $J$. Elect. Spect. Relat. Phenom. 153 (2006), pp. 96-101. 